\title{
Angiogenesis Promoter
}

National Cancer Institute

\section{Source}

National Cancer Institute. Angiogenesis Promoter. NCI Thesaurus. Code C18574.

Natural factors which stimulate blood vessel production. 